genation of iso-propanol is being used to examine different forms of digital control. The computer used is an ARCH 9000 . During the past year, the instruments and computer systems of the plant have been modified and extended in various ways. It is only by re-designing the plant and processes that the full possibilities of computer control can be gauged. Short specialized training courses for chemical engineers from industry are being held at the laboratory so that detailed knowledge of the methods and techniques of process control may be diffused through the process industries. A second project to study computer control has now been started. This is a study of the control by computer of a fast chemical reaction (oxidation of hydrocarbons) in a transfer-line reactor, in which effective control to obtain conditions of maximum conversion can be done only by computer. The work so far has been mainly on computer control of large-scale and complex continuous processes. The laboratory has found, however, that there could also be improved control of a number of processes on a smaller scale. Research has been started, therefore, on control of batch distillation with an assembly of digital logic and analogue elements.

Several other investigations are described in the report. These include work on viscometers and flowmeters, and the development of an on-line particle size sensor and a new fluorine analyser based on neutron activation. The work on flow properties, mixing storage and bulk-handling of granular materials has led to designs for mass-flow hoppers. These have been successfully applied in a number of different industries.

It has been estimated recently that air pollution costs Britain $£ 350$ million annually, quite apart from any losses caused by its effect on health. The laboratory spends just over 20 per cent of its total expenditure on research in this field. In 1966, increased attention was paid to pollution arising from vehicular traffic and to the reactions of pollutants in the atmosphere.

\section{Coexistence in Botany}

SnNCE the merger in September 1967 of the Departments of Botany and Agricultural Botany at the University College of North Wales, Bangor, a noteworthy effort has been made to break down the barrier between pure and applied plant sciences.

The School of Plant Biology-as it is now calledwas instigated by Professor P. W. Richards with the aim of covering the widest possible range of botanical subjects and with the intention of ending the separation between pure and applied disciplines. According to Professor J. L. Harper, who is head of the new school, the union has brought in an academic staff of twentythree, and a number of building alterations have made it possible to house almost all the academic staff in one main building. Teaching and some research activities are, however, still spread over a number of buildings.

The school now possesses two field stations. One of these is the 28 acre research station of the School of Agriculture at Pen-y-ffridd: it has research laboratories, and controlled environment facilities are provided. The other station-Treborth botanic garden-is approximately the same size and has laboratories, woodland and an experimental garden. The greater part of the work in systematics is concentrated at Treborth, and physiology and experimental ecology are developed at Pen-y-ffridd.

Within the school there are now two M.Sc. courses -one in pure and applied ecology and a second in crop protection. The latter with an intake of about ten graduates a year is particularly valuable, according to Professor Harper, for strengthening the links with agricultural industry.

Undergraduates are, however, the main interest in the school, which still offers degrees in agricultural botany and botany. Students are offered an extremely wide range of choices in the honours degree option, so that a student can specialize in an aspect of the plant sciences covering both pure and applied science disciplines. The merger has also produced a very large research group and there are at present thirty-four students working for postgraduate degrees - a healthy number for any university department. Part of the finance is provided by the Science Research Council, part by the Natural Environment Research Council, and the Ministry of Agriculture provides studentship awards. But in addition there are a number of students engaged in work supported by industry, and there are also students supported by the Copper Development Association, the Zinc Development Association and the International Copper and Zinc Research Association.

\section{Parliament in Britain}

\section{Agriculture}

Mrs Shrrley Williams, Minister of State, Department of Education and Science, stated that in the United Kingdom in 1966, 431 students qualified for university first degrees in agricultural subjects and 194 for higher degrees or diplomas. In 1967, 482 qualified for diplomas, 1,799 for certificates following full-time courses and about 13,000 for certificates in individual subjects following part-time or block release courses in further education. (Written answer, January 25.)

\section{Power}

The Parliamentary Secretary to the Ministry of Power, Mr R. Freeson, stated that the inclusion of the allowance for the effect of devaluation changed the estimate of the cost of electricity from Dungeness $B$ nuclear power station from $0.56 d$. to $0.57 d$. $/ \mathrm{kWh}$. The effect on the operating costs at Hunterston $A$ station was likely to be marginal and at Hunterston $B$ was unlikely to be significant, although depending largely on the final terms of individual contracts. The total consumption of fuel oil at power stations in the United Kingdom was estimated at $7 \cdot 3$ million tons in 1966 and $7 \cdot 4$ million tons in 1967. Mr R. Marsh, Minister of Power, stated that the Central Electricity Generating Board estimated the construction cost of Hinkley Point $B$ at $£ 71 / \mathrm{kW}$ and the base load generating cost, including capital charges, at $0.52 d . / \mathrm{kWh}$. For Drax, the most advanced coal-fired thermal power station offered to the board, the corresponding figures are $£ 52 / \mathrm{kW}$ and $0 \cdot 60 d . / \mathrm{kWh})$. He was advised by the board that with pithead coal prices of $3 d ., 4 d ., 5 d$. and $6 d$. per therm, the estimated base load generation cost per $\mathrm{kWh}$ of the most advanced coal-fired power station would be $0 \cdot 55 d$., $0 \cdot 65 d ., 0 \cdot 74 d$. and $0 \cdot 83 d$., respectively. (Written answers, January 19, 22 and 23.) 